Check for updates

Cite this: RSC Adv., 2018, 8, 19739

Received 15th January 2018

Accepted 30th April 2018

DOI: $10.1039 / c 8 \mathrm{ra00440d}$

rsc.li/rsc-advances

\section{Strategies to synthesize various nanostructures of silver and their applications - a review}

\author{
Umme Thahira Khatoon, (D) *a G. V. S. Nageswara Rao, ${ }^{a}$ Krishna Mohan Mantravadia \\ and Yasemin Oztekin ${ }^{\mathrm{b}}$
}

Due to their various beneficial application-based properties, such as behavior, structure, and size, the synthesis of silver nanoparticles (Ag-NPs) with different structures has become an interesting yet common task for researchers to produce nanostructures for applications in various fields. This is because silver nanoparticles have interesting and unique properties, such as optical and catalytic, resulting from their different structures and sizes. These properties extend the use of nanostructures in various fields of research, especially in medicine, pharmacy, electronics, etc. Also, variations in their parameters affect the structures and sizes of Ag-NPs. This review provides an overview/brief presentation of various methodologies used to synthesize different application-based silver nanoparticles and lists areas where these nanoparticles are suitable for use according to their specific structures and sizes.

\section{Introduction}

Nanotechnology is an advanced and modern field with novel research involving the synthesis and design of structures sized from 1 to $100 \mathrm{~nm}$. Nanostructures have a broad range of

${ }^{a}$ Department of Metallurgical and Materials Engineering, National Institute of Technology, Warangal, Telangana State, India. E-mail: ummethahirakhatoon@ gmail.com; ummethahirakhatoon@nitw.ac.in; nr_gvs@yahoo.com; gvsnr@nitw.ac. in; mkmohan1@yahoo.com; mkmohan@nitw.ac.in

${ }^{b}$ Department of Chemistry, Faculty of Science, Selcuk University, Konya, Turkey. E-mail: yoztekin@gmail.com

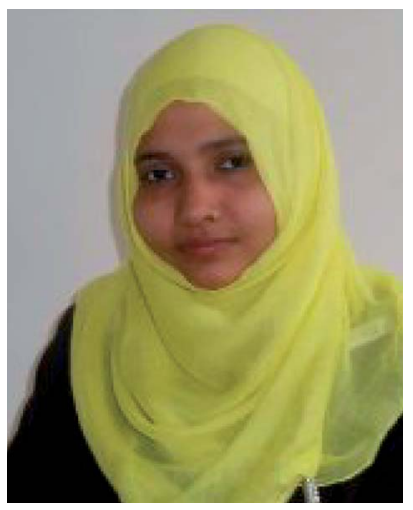

Ms. Umme Thahira Khatoon is a research scholar in the department of Metallurgical and Materials Engineering at the National Institute of Technology, Warangal, India. Her area of $\mathrm{PhD}$ research is the synthesis of metal nanoparticles and their antimicrobial/anticancer properties. She received her B. Tech (Biotechnology) and M. Tech (Nanotechnology) degrees in 2008 and 2011, respectively, from Jawaharlal Nehru Technological University, Hyderabad, India. During her studies, she attended and participated in international conferences, with paper and poster presentations in and outside India. Her research interests include the synthesis of nanomaterials and their biomedical applications as aspects of nanotechnology. applications. ${ }^{1}$ Nanostructures play roles in areas such as health care, cosmetics, food and feed, environmental health, mechanics, optics, and biomedical sciences. They are also important in the fields of chemical industries, electronics, space industries, drug-gene delivery, energy science, optoelectronics, catalysis, single electron transistors, light emitters, nonlinear optical devices, and photoelectrochemical applications. ${ }^{1-6}$ Researchers have synthesized nanoparticles with various interesting shapes, such as ellipsoidal, spherical, flowers, rods, stars, triangles, and tubes. There are different methods to synthesize metal nanostructures containing silver. These nanostructures can be obtained by physical, chemical

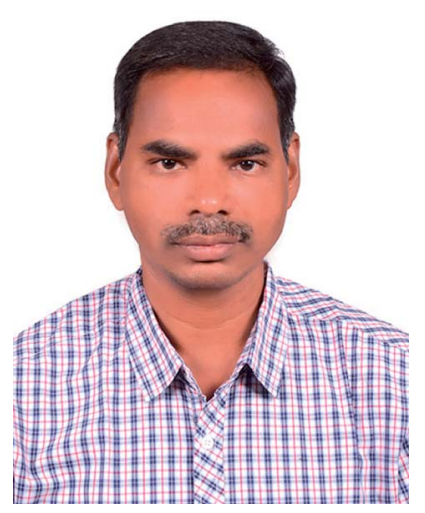

Prof. Dr. G. V. S. Nageswara Rao is a professor in the Department of Metallurgical and Materials Engineering at the National Institute of Technology, Warangal, India. His research interests are surface engineering, powder metallurgy, materials testing and characterization, thermomechanical processing, and nanomaterials. He has several research publications, books, DST/AICTE/MHRD and other sponsored projects to his name. Prof. G. V. S. Nageswara Rao has research specialization as: Surface Engineering, Powder Metallurgy, Materials Testing and Characterization, Thermomechanical Processing, Nanomaterials. 
and biological methods. Physical and chemical methods are used by many researchers., ${ }^{7,8}$ Biological methods are ecofriendly and non-toxic to the environment; these approaches include using metabolites as stabilizing and capping agents. $^{9-11}$

Among the three methods, biological methods have advantages over conventional methods, which involve chemical agents associated with environmental toxicity. Currently, there is a growing need to develop eco-friendly processes which do not use toxic chemicals in synthesis methodologies. Selection of the solvent medium and of non-toxic reducing and stabilizing agents is the most important issue to be considered in the synthesis of nanoparticles. Ag-NPs are in demand among other metal nanoparticles due to their unique properties, which can be incorporated into antimicrobial applications. $^{\mathbf{1 2 , 1 3}}$ These include biosensor materials, ${ }^{\mathbf{1 4 , 1 5}}$ composite fibers, ${ }^{16-18}$ cryogenic superconducting materials, ${ }^{19,20}$ cosmetic products, ${ }^{21,22}$ and electronic components. ${ }^{23,24}$ Several physical and chemical methods have been used for synthesizing and stabilizing silver nanostructures. ${ }^{25,26}$ The various sub methods of chemical methods include chemical reduction, electrochemical techniques, physical/chemical reduction and radiolysis. In comparison, the chemical reduction method has greater potential to synthesize a variety of nanostructures while changing several parameters involved in the synthesis of the nanostructures. Most of these methods are in the development stage and involve crystal growth, morphology, and size distribution and stability. Moreover, purification and extraction of nanoparticles for further applications are still significant concerns. $^{27-30}$

This review presents an overview of the synthesis methods of silver nanostructures with different shapes for different applications.

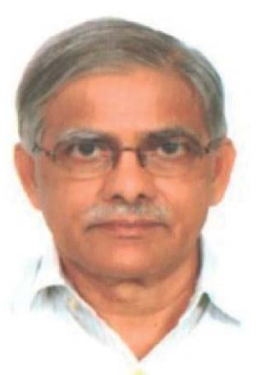

Dr. M. K. Mohan is a Professor at the National Institute of Technology, Warangal (India). He received his $P h D$ from the Institute of Technology, Banaras Hindu University (India) in 1989. He visited The University of Alabama, Tuscaloosa, Alabama (USA) as a Post-Doctoral Fellow in 1998. He is Professor in charge at the Center for Advanced Materials. His research interests are corrosion engineering, extractive metallurgy and chemical synthesis of nanomaterials.

\section{Methods of synthesis}

Various methods are involved in synthetic chemical procedures for the synthesis of nanostructures. Researchers have reported that various factors, such as temperature and concentration of metal precursors or chemicals, are used to optimize the growth and morphological behavior of the particles. ${ }^{31}$

\subsection{Lee Miesel method}

The Lee Miesel method is a common method to synthesize suspensions of Ag-NPs. This method uses many metal sources rather than only $\mathrm{AgNO}_{3}$, unlike the Turkevich method. ${ }^{32}$ Also, the Lee Miesel method produces a broad distribution of particle sizes. There are many examples where $\mathrm{Ag}$ salts and reducing agents were used. ${ }^{33-37}$ However, the most common method to synthesize $\mathrm{Ag}$-NPs is reduction of $\mathrm{AgNO}_{3}$ with $\mathrm{NaBH}_{4} \cdot{ }^{38}$

$\mathrm{Yu}$ Wan et al. described a robust method for the stable synthesis of quasi-spherical Ag-NPs. The method is based on a combination of seed-mediated growth and the Lee Miesel method. This synthesis includes the reduction of $\mathrm{AgNO}_{3}$ with citrate. Ag-NPs with sizes from $4 \mathrm{~nm}$ to $80 \mathrm{~nm}$ were obtained. Crucial factors such as $\mathrm{pH}$, temperature, time, and concentration were also discussed during the synthesis. Fig. 1 and 2 present the growth of Ag-NPs obtained using the Lee Miesel reduction system and SEM images of Ag-NPs. ${ }^{39}$ Alexander Pyatenko et al. described a combination of the seed technique with laser treatment to synthesize Ag-NPs with diameters of 10 to $80 \mathrm{~nm}$ using a citrate reduction of $\mathrm{AgNO}_{3}$. Particles larger than $60 \mathrm{~nm}$ were produced using a multistep synthesis with laser treatment. The most important factor was soft laser treatment, which helped the heating and melting of the particles. However, measures were also taken to avoid evaporation of the nanoparticles. Furthermore, soft laser fluence had no effect on the size of the particles. ${ }^{40}$

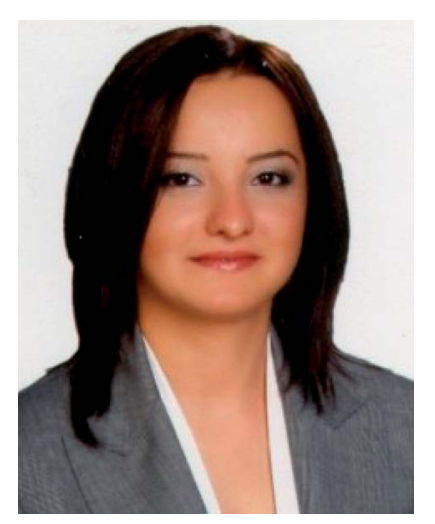

Dr. Yasemin Oztekin is an associate professor at Selcuk University, Konya, Turkey. She completed her PhD at Selcuk University, Turkey and a post doctorate at Vilnius University, Lithuania. She has more than 11 years of academics and research experience at Selcuk University. Also, she has successfully supervised 3 doctoral students. Her research interests are electrochemistry, nanomaterials and nanostructures. To her credit, she has published more than 42 research articles in standard journals. Also, she served as the Selcuk University-Montana State University International Associate Degree Program Bio Biochemistry Division Coordinator, Selcuk University Chemistry Department ERASMUS Program Coordinator and Selcuk University Chemistry Department Mevlana Program Coordinator. 

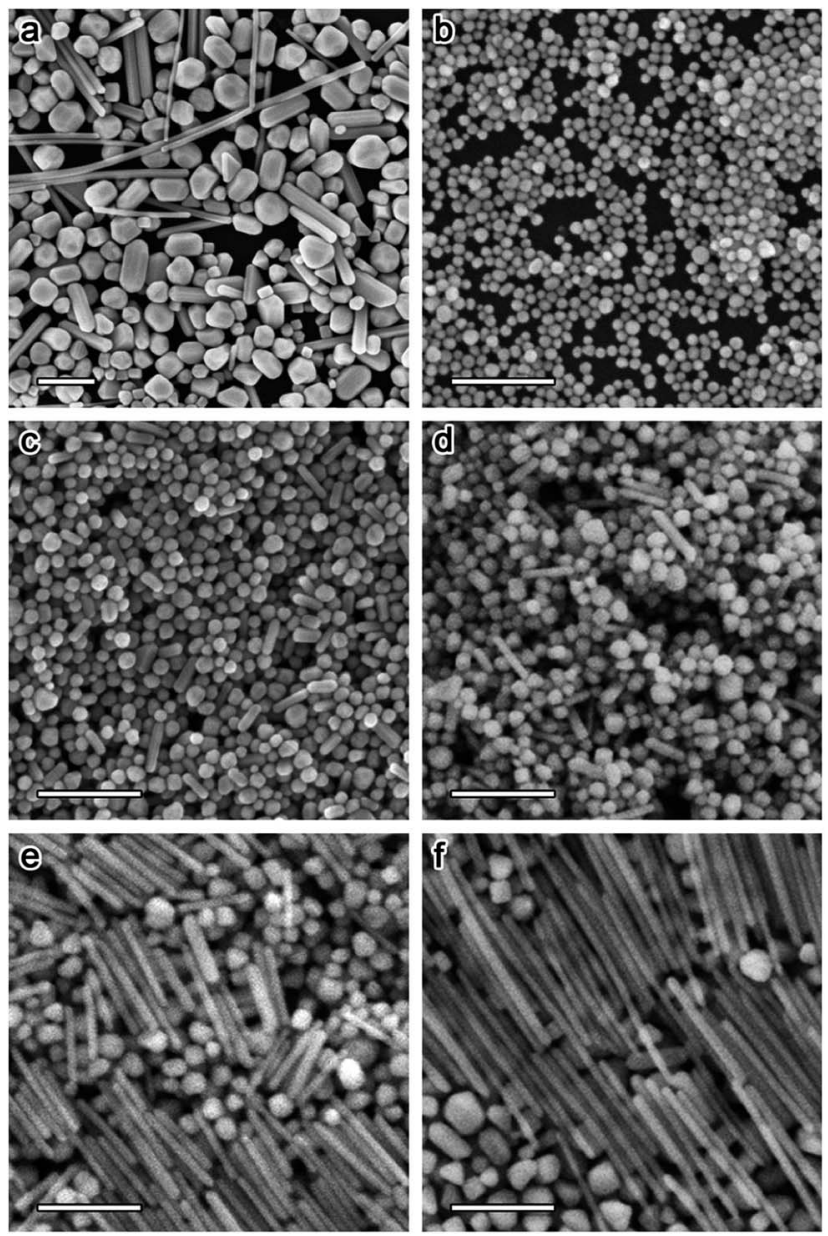

Fig. 1 (a) SEM image of Ag-NPs obtained by the Lee-Meisel method. $(b-f)$ : SEM images of Ag-NPs obtained by a combination of the LeeMeisel method with seeded growth. ${ }^{39}$

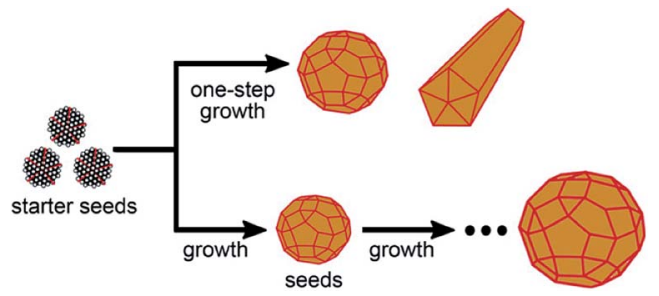

Fig. 2 Schematic of one-step and stepwise seeded growth of Ag-NPs in the Lee-Meisel reaction system. ${ }^{39}$

\subsection{Chemical reduction method}

Ratan Das et al. presented the optical properties of nanocubes and nanocrystals which were prepared by chemical reduction methods. They confirmed that the nanocubes were stable for two months by SPR red shift. ${ }^{41}$ After two months, the particles started to agglomerate, indicating an aging process; the optical properties were defined by photoluminescence spectra after two months, which showed color changes and red-shifted SPR. Ratan Das et al. stated that temperature is the key factor during synthesis for a narrow distribution of nanocubes; the ideal temperature was determined to be $170{ }^{\circ} \mathrm{C}$ with $500 \mathrm{rpm}$ stirring speed. ${ }^{\mathbf{4 1 , 4 2}}$ The average particle size obtained using the Debye Scherrer formula ${ }^{43-45}$ was in agreement with the ICSD file. ${ }^{46-49}$ They confirmed that the size of the noble metal nanostructures increased beyond $20 \mathrm{~nm}$; the bandwidth of SPR also increased due to the extrinsic size effect. ${ }^{41}$ Absorption and emission spectra, which determine the optical properties, were obtained in the visible range with $100 \mathrm{~nm}$ size distribution. Sang Hyuk Im et al. synthesized nanocubes with dimensions of $1.2 * 12 \mathrm{~nm} 21$ $\mathrm{nm} ; 130 \mathrm{~nm}$ wide using $\mathrm{HNO}_{3}, \mathrm{NaCl}$ and $\mathrm{Cl}^{-} / \mathrm{O}_{2}$ as etchants in a chemical process. ${ }^{50}$ Using this particular process, they were able to synthesize $0.25 \mathrm{gm}$ of material. This indicates that the above process is robust and can be used to produce large-scale nanostructures. They also stated that the presence of protons slowed the reduction reaction and facilitated the formation of crystal seeds. ${ }^{50}$ Yun-Min Chang et al. synthesized Ag nanocubes with a heat treatment process using glucose, ${ }^{51,52}$ which is also known to be a mild reducing agent. The chemicals were autoclaved at $120{ }^{\circ} \mathrm{C}$ for $8 \mathrm{~h}$ to catalyze the process. The chemical reaction of the $\mathrm{Ag}$ nanocubes is shown in eqn (1).

$\mathrm{CH}_{2} \mathrm{OH}-(\mathrm{CHOH})_{4}-\mathrm{CHO}+2\left[\mathrm{Ag}\left(\mathrm{NH}_{3}\right)_{2}\right]^{+}+2 \mathrm{OH}^{-} \rightarrow \mathrm{CH}_{2} \mathrm{OH}-$
$(\mathrm{CHOH})_{4}-\mathrm{COOH}+2 \mathrm{Ag}+\mathrm{H}_{2} \mathrm{O}+2 \mathrm{NH}_{3}$

It is also evident from other studies that cetyl trimethyl ammonium bromide (CTAB) absorbed on the surface of nanoparticles provides steric hindrance, which prevents the coalescence of aggregates during the formation stage in solution due to weak van der Waals forces. When these particles are dried, they tend to retain a uniform size distribution. ${ }^{53}$ A change in morphology when the molar ratio of glucose/silver ions was changed was also described; the yields of the silver nanocubes were estimated to be greater than 95\%. Qiang Zhang et al. provided a method to synthesize nanocubes with 30 to $70 \mathrm{~nm}$ edge lengths; this synthesis could be scaled up to $0.19 \mathrm{~g}$ per batch for $70 \mathrm{~nm}$ of $\mathrm{Ag}$ cubes. ${ }^{54}$ Many methods have been utilized to synthesize $\mathrm{Ag}$ nanocubes using different metal precursors, such as $\mathrm{CF}_{3} \mathrm{COOAg}$, instead of $\mathrm{AgNO}_{3} \cdot{ }^{55-61}$ This has three advantages: using the reaction time to control the size of the $\mathrm{Ag}$ nanocubes; lack of sensitivity to ethylene glycol, thus improving the strength/robustness and reproducibility of the polyol synthesis; and straightforward and large-scale production with high quality. Also, TEM images presented for different reaction times prove that using $\mathrm{NaSH}$ and $\mathrm{HCl}$ is necessary for the production of nanoparticles of uniform structure and size. It has also been mentioned that in this method, $\mathrm{NaSH}$ plays a role in the formation of single crystal seeds and $\mathrm{Cl}^{-}$ions function as a ligand for oxidative etching to eliminate twinned particles. Hence, this method is not sensible to ethylene glycol because it is sensitive towards polyol synthesis.

\subsection{Polyol process}

The polyol process is a chemical method where metals are synthesized from metal-containing compounds in poly(ethylene glycols). Ethylene glycol acts as both the solvent and reducing agent. ${ }^{62}$ Seog-Jin Jeon et al. synthesized Ag-Nps using $\mathrm{HNO}_{3}$ to 


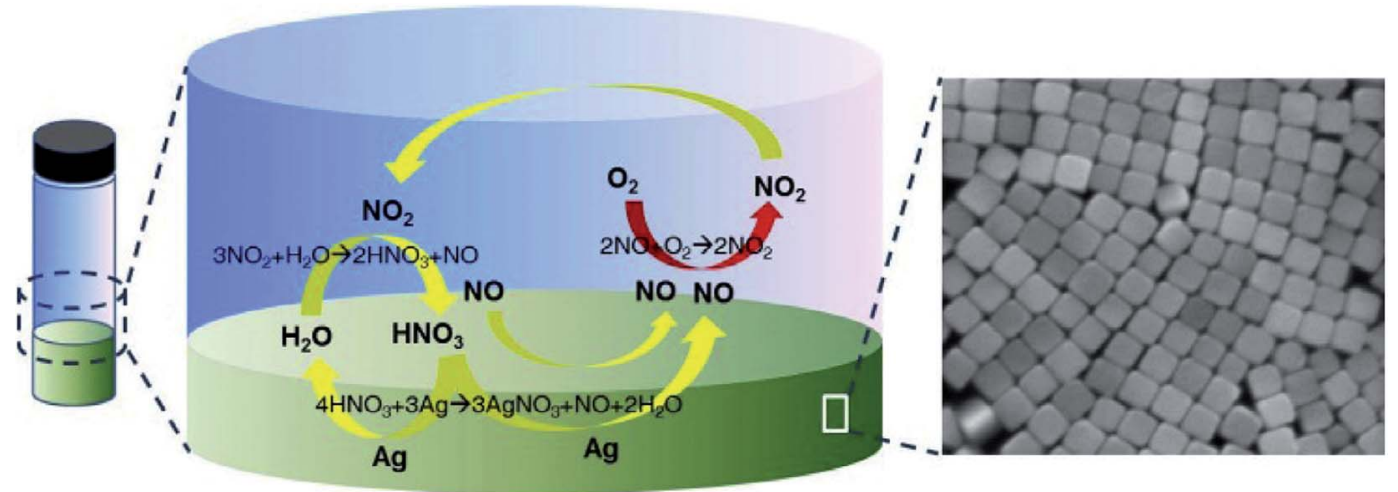

Fig. 3 Working hypothesis for the deoxygenation process. ${ }^{63}$

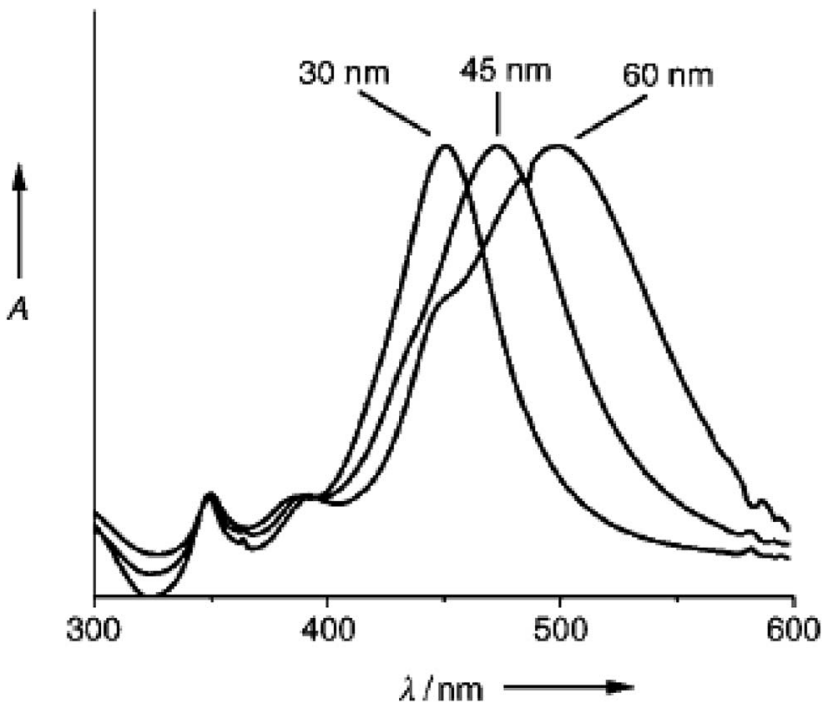

Fig. $4 \mathrm{UV} / \mathrm{vis}$ absorption spectra of aqueous solutions containing silver nanocubes with different edge lengths $(30 \mathrm{~nm}, 45 \mathrm{~nm}$, and 60 $\mathrm{nm})^{64}$

initiate the process with minimal glycol aldehyde along with silver nitrate. ${ }^{63}$ The formation of nanocubes and nanowires was due to etching. Fig. 3 presents the principle of deoxygenation behind the production of nanocubes.

Sang Hyuk Im et al. have put forward a protocol to synthesize nanocubes on a grand large scale by introducing $\mathrm{HCl}$ to a simple polyol process where the $\mathrm{HCl}$ played a major role in etching and dissolving twinned Ag-NPs. ${ }^{50}$ Eqn (2)-(4) explain the formation of the nanoparticles.

$$
\begin{gathered}
2 \mathrm{HOCH}_{2} \mathrm{CH}_{2} \mathrm{OH} \rightarrow 2 \mathrm{CH}_{3} \mathrm{CHO}+2 \mathrm{H}_{2} \mathrm{O} \\
2 \mathrm{Ag}^{+}+2 \mathrm{CH}_{3} \mathrm{CHO} \rightarrow \mathrm{CH}_{3} \mathrm{CHO}-\mathrm{OHCCH}_{3}+2 \mathrm{Ag}+2 \mathrm{H}^{+} \\
4 \mathrm{HNO}_{3}+3 \mathrm{Ag} \rightarrow 3 \mathrm{AgNO}_{3}+\mathrm{NO}+2 \mathrm{H}_{2} \mathrm{O}
\end{gathered}
$$

Sang Hyuk Im et al. synthesized nanocubes with different edge lengths of $30 \mathrm{~nm}, 45 \mathrm{~nm}$, and $60 \mathrm{~nm}$, as shown in Fig. 4..$^{\mathbf{5 0 , 6 4}}$ Sara E. Skrabalak et al. described a protocol for the preparation of $\mathrm{Ag}$ nanocubes in a rapid reaction time of $15 \mathrm{~min}$ using a polyol method, where the color of the sample changed from purple/black to yellow-orange to brown-opaque-red to greenochre. ${ }^{65}$ Sara E. Skrabalak et al. are among the few researchers who have described the phenomenon of Ag-NPs formation as Ag atoms reach supersaturation. ${ }^{65}$ They agglomerate to form seeds and then grow into $\mathrm{Ag}$ nanostructures, which is the core formation process of any nanoparticle. ${ }^{66}$ Yugang Sun et al. attempted a large-scale synthesis of $\mathrm{Ag}$ nanowires with diameters of 30 to $40 \mathrm{~nm}$ and lengths of $50 \mu \mathrm{m}$; they presented the properties of the nanowires, describing them as electrically continuous with a conductivity $\left(-0.8 \times 10^{5} \mathrm{~S} \mathrm{cn}^{-1}\right)$ approaching that of bulk silver. ${ }^{67}$ Table 1 presents the procedures used to obtain the product. Yugang Sun et al. presented an interesting method of a Pt-seeded polyol process to prepare silver nanowires. UV-vis SPR showed a peak at $530 \mathrm{~nm}$, indicating the formation of rod-like structures, whereas the UV-vis spectrum showed a peak at $410 \mathrm{~nm}$ that red-shifted to $510 \mathrm{~nm}$, showing a change of the structures from spheres to rods. Fig. 5 and 6 show the different mechanisms involved in synthesizing nanowires. ${ }^{69,72,73}$ Nanowires have been prepared by many methods; the mechanisms corresponding to the different methods are shown in Fig. 7 and $8 .^{74,75}$ The researchers also stated that surface roughness can be minimized by depositing thin and long Ag NWs on polymer matrices. ${ }^{68-71}$

\subsection{Electrochemical method}

Cai Hong Liu et al. presented the application of silver nanowires (NW) as a transparent flexible and conductive thin film. The NWs were also applied as electrodes, where silver nanowires were preserved in isopropyl alcohol using polyethylene terephthalate [PET] as a substrate to prepare the electrodes. ${ }^{76}$ Fig. 9 presents nanowires with different sizes. ${ }^{77}$ Rodriguez et al. described an electrochemical procedure to synthesize Ag-NPs ranging from 2 to $7 \mathrm{~nm}$ in size by dissolving a metallic anode in an aprotic solvent. Ag-NPs were obtained by reduction of silver ions in acetonitrile containing tetrabutylammonium salts (TBA bromide or TBA acetate). It has been noted that current density plays an important role in maintaining particle size as well as the efficiency of the process. ${ }^{77}$ 
Table 1 Products obtained when the reactants were added using different procedures ${ }^{a}$

\begin{tabular}{|c|c|c|}
\hline $\begin{array}{l}\text { Sample } \\
\text { no. }\end{array}$ & Procedure & Product \\
\hline AG04 & $\begin{array}{l}2.5 \mathrm{~mL} \mathrm{AgNO} \text { and } 5 \mathrm{~mL} \mathrm{PVP} \mathrm{solutions} \mathrm{were} \\
\text { simultaneously injected using syringes within } \\
\text { a period of } 6 \text { min (the standard procedure } \\
\text { described in the Experimental section) }\end{array}$ & $\begin{array}{l}\text { A mixture of silver nanowires }(70 \%) \text { and } \\
\text { colloidal particles }(30 \%)\end{array}$ \\
\hline AG12 & $\begin{array}{l}1 \mathrm{~mL} \text { PVP solution was injected within } 10 \mathrm{~s} \\
\text { before the addition of } \mathrm{AgNO}_{3} \text {, and the } \mathrm{AgNO}_{3} \\
(2.5 \mathrm{~mL}) \text { and PVP }(4 \mathrm{~mL}) \text { solutions were } \\
\text { simultaneously injected within a period of } 6 \mathrm{~min}\end{array}$ & $\begin{array}{l}\text { A mixture of silver nanorods }(10 \%) \text { and particles } \\
(90 \%)\end{array}$ \\
\hline AG35 & $\begin{array}{l}5 \mathrm{~mL} \text { PVP solution was injected within } 10 \mathrm{~s} \text {, and } \\
2.5 \mathrm{~mL} \mathrm{AgNO}_{3} \text { solution was then injected within } \\
\text { a period of } 10 \mathrm{~s}\end{array}$ & Silver nanoparticles only \\
\hline AG36 & $\begin{array}{l}5 \mathrm{~mL} \text { PVP solution was injected within } 10 \mathrm{~s} \text {, and } \\
2.5 \mathrm{~mL} \mathrm{AgNO}_{3} \text { solution was then injected within } \\
\text { a period of } 6 \mathrm{~min}\end{array}$ & Silver nanoparticles only \\
\hline
\end{tabular}

\subsection{Electrodeposition method}

Nasir M Abbasi et al. presented different synthetic techniques for the preparation of Ag-NWs, indicating the effects of various factors, such as temperature, time, rate, materials, and inert conditions. ${ }^{78}$ They also proved that the Ag-NWs have high electrical conductivity, a high surface area, and a high aspect ratio, which are essential for the preparation of Ag-NWs/ conducting polymer nanocomposites. Useful applications include touch screens, liquid crystal displays, and solar cells. ${ }^{78}$

\subsection{Biological method}

Cheng Yang et al. attempted to produce nanowires (NWs) by green methods rather than polyol, chemical reduction or other chemical-based methods. To synthesize nanowires, they used water and glycerol as reducing agents and solvents at a high temperature $\left(210{ }^{\circ} \mathrm{C}\right)$ in an optimal ratio of $0.25 \%$. They also observed that a small amount of water increased the yield of the nanowires. ${ }^{79}$ When $\mathrm{NaCl}$ and $\mathrm{KCl}$ were used as controlling agents, they observed the formation of 60 to $70 \mathrm{~nm}$ nanowires, respectively. They also observed this method to be simple and reproducible compared to other methods. ${ }^{79}$ In another investigation, glycerol was used as a reducing agent instead of EG, in contrast to nanostructures syntheses reported by other researchers. ${ }^{80}$ An optimum ratio of water/glycerol $(0.25 \%)$ was necessary to produce nanowires; otherwise, the presence of other shapes was observed. Xiao lian Jing et al. synthesized nanoflowers via a biosynthesis method using Flos-Magnolia E.

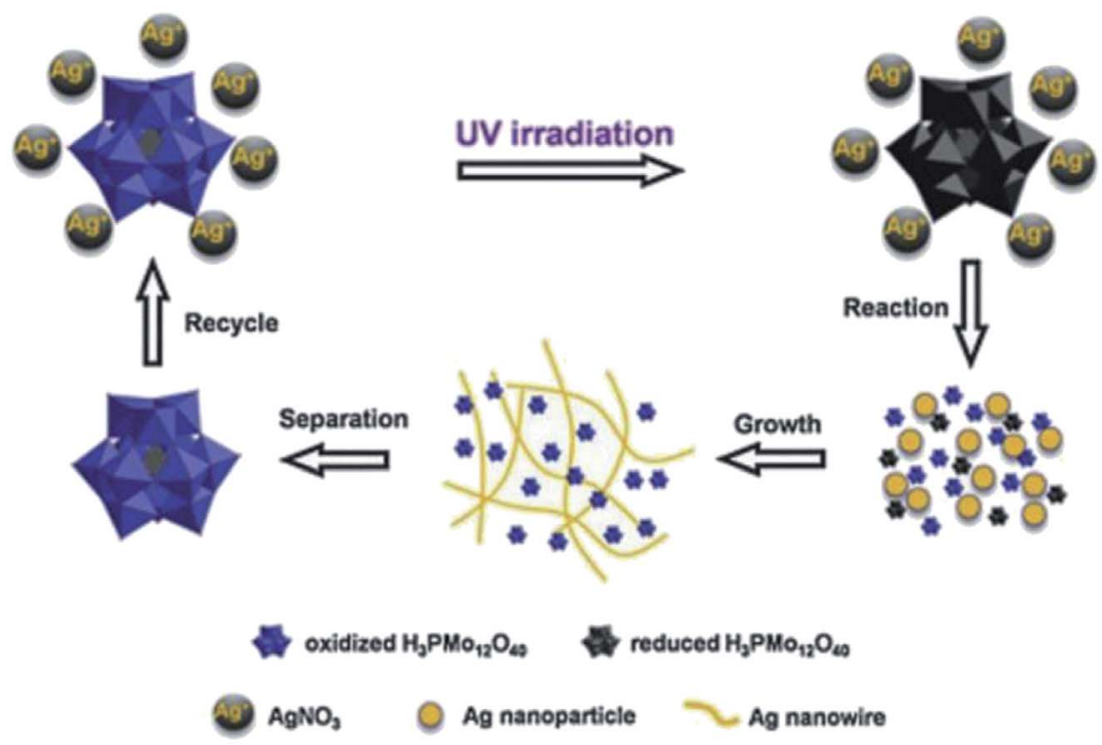

Fig. 5 The processes involved in the preparation of Ag-NWs. ${ }^{69}$ 


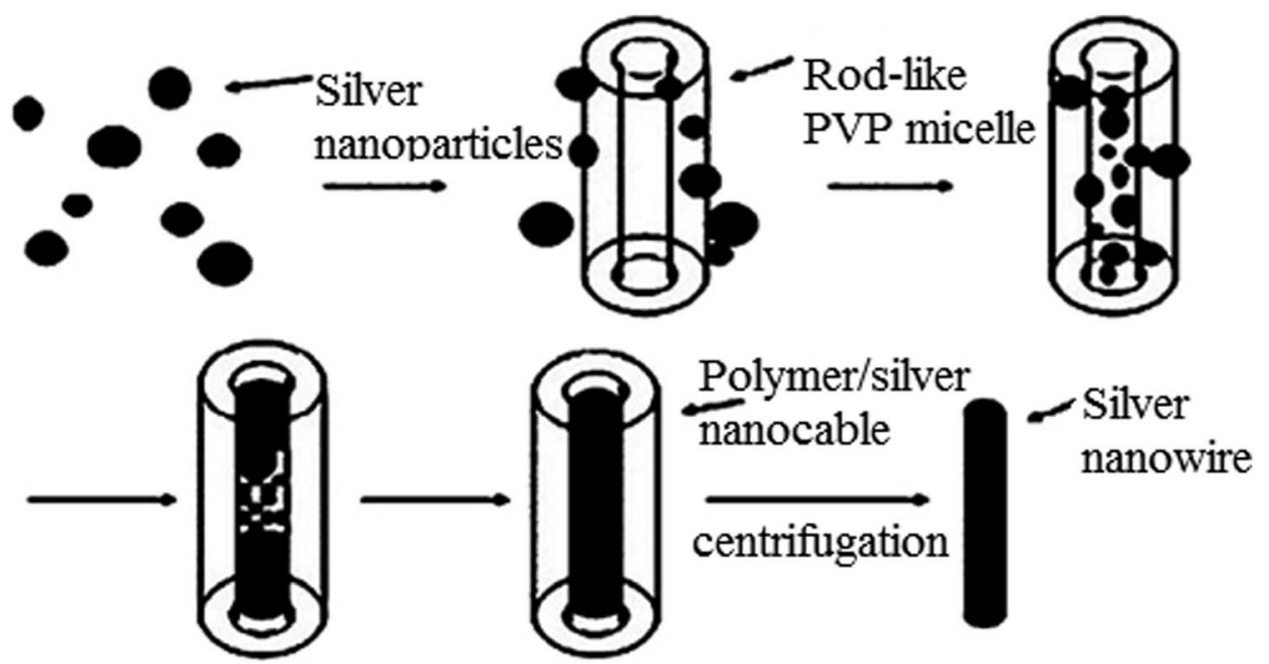

Fig. 6 Formation process of Ag-NWs. ${ }^{69}$

officinalis extract and compared this method with a green synthesis involving reducing and stabilizing agents. Polyphenols played the main role in the reduction and synthesis of nanoflowers. They also reported that in the green synthesis, no stabilizing agent was used; different shapes of $\mathrm{Ag}$ nanoproducts, such as spheres, ellipsoids, and rods, could be prepared by varying the amounts of trisodium citrate $(1 \mathrm{M})$ and gallic acid. For example, $1: 1$ and $0.5: 1$ ratios of the metal precursor and reducing agent were used. The TEM micrographs obtained by these investigators are shown in Fig. 10. ${ }^{81}$ Fig. 11 shows a schematic of the formation of $\mathrm{Ag}$ nanoflowers. Bikash Kumar et al. applied bio-inspired techniques to synthesize branched flowerlike $\mathrm{Ag}$ nanostructures which could be implemented in surface enhanced Raman scattering (SERS) and antibacterial activity. ${ }^{\mathbf{8 1 , 8 2}}$ The shape, size and surrounding medium of the particles were studied by UV-vis optical spectra with surface plasmon resonance (SPR) wavelengths $(438 \mathrm{~nm}$, $600 \mathrm{~nm}) .{ }^{83,84}$ Also, the spherical NPs were formed by reducing $\mathrm{Ag}^{+}$with rutin; with time, the structure of the NPs changed to short branches. After that, further nucleation and assembly took place, and the crystals finally grew into flower-shaped nanostructures. Also, with increasing concentration of rutin, the shape of particles changed.

Ma Xinfu et al. followed an eco-friendly route to synthesize nanoflowers. This biosynthesis route used L-cysteine as a reducing agent and capping agent in alkaline solution in

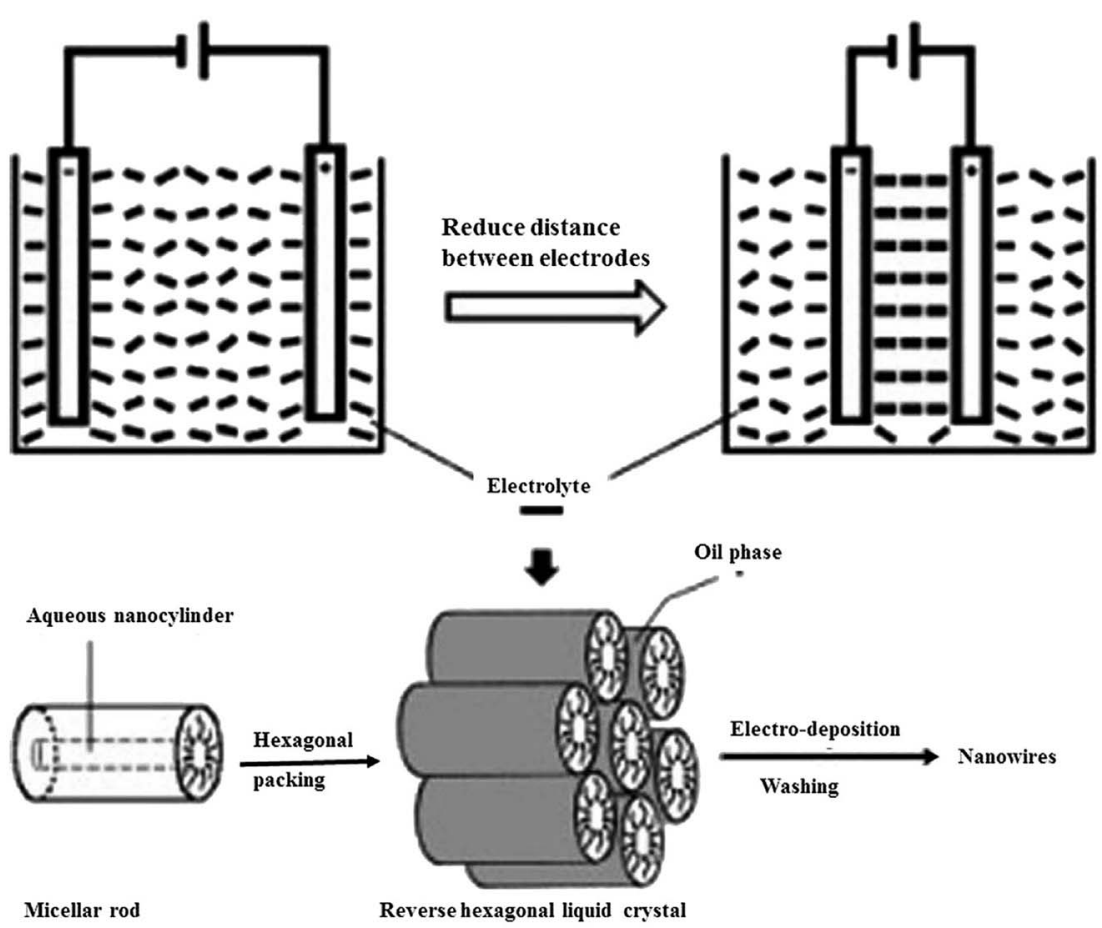

Fig. 7 Process of the enhanced alignment of the reverse hexagonal liquid-crystalline phase during nanowire electro-deposition. ${ }^{74}$ 

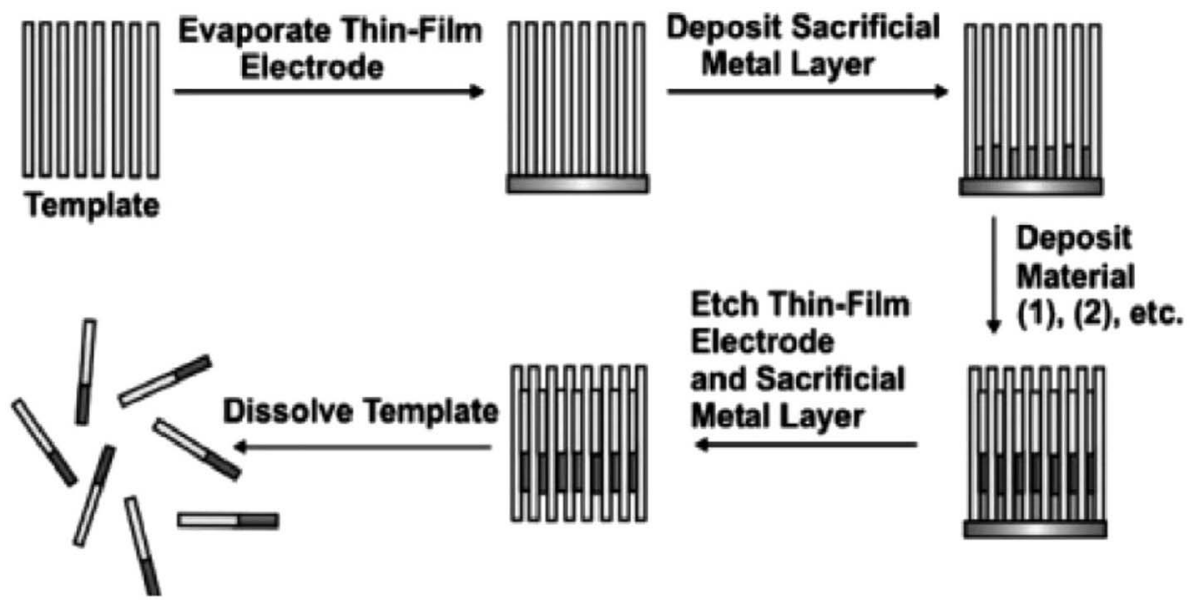

Fig. 8 General scheme for the synthesis of one-dimensional nanostructures (nanowires and nanorods) by the deposition of materials into nanoporous templates. ${ }^{75}$

a $70{ }^{\circ} \mathrm{C}$ water bath. ${ }^{85}$ This biological approach is simple, convenient and significant for preparing stable metal nanostructures in an aqueous medium.

\section{Different shapes of silver nanostructures}

\subsection{Silver nanocubes}

Xia et al. synthesized Ag nanocubes with edge lengths of $115 \pm 9$ and $95 \pm 7 \mathrm{~nm}$ using ethylene glycol to reduce $\mathrm{AgNO}_{3}{ }^{\mathbf{8 6 , 8 7}}$ Dabin $\mathrm{Yu}$ et al. reported another approach to produce silver nanocubes with sizes of $55 \pm 5 \mathrm{~nm}$ using a silver mirror reaction approach. ${ }^{86,88}$ The silver mirror reaction is an old chemical route to generate reflective mirrors on solid supports. ${ }^{89}$

$\mathrm{Ag}$ nanocubes were prepared at high temperatures above $80{ }^{\circ} \mathrm{C}$. Similarly, there are reports on the synthesis of $\mathrm{Ag}$ nanocubes which were used as templates for gold nanoboxes and iron nanocubes, which were then used as building blocks of magnetic superlattices. ${ }^{87,90}$ XRD analysis of the Ag nanocubes indicated that the product stretches in a preferential ${ }^{\mathbf{1 0 0}}$ orientation, as the [200] intensity was three times greater than that of. ${ }^{\mathbf{1 0 0}}$ This observation indicates the ability of the Ag nanocubes to assemble into a $2 \mathrm{D}$ array on a solid surface. ${ }^{91}$ Dabin $\mathrm{Yu}$ et al. were able to produce uniform nanocubes, as shown in Fig. 12.92

Also, they mentioned that increasing the molar ratio of $\mathrm{HTAB} /[\mathrm{Ag}(\mathrm{H} 3) 2]^{+}$led to an obvious shape evolution of the $\mathrm{Ag}$ nanostructures from spheres to cubes due to adsorption of the surfactant on the surface of the silver crystal faces; these adsorption characteristics depended on the molar ratio. The minimum molar ratio to form nanocubes is $2.5 \mathrm{M}$, where the sample color changed from orange to yellow in agreement with the UV-vis spectra peak at $420 \mathrm{~nm}$; this may lead to general and mechanical applications of these nanocubes. E. V. Panfilova et al. stated that the abovementioned method was not efficient for controlling the size of cubic particles; changing the reagent concentration $^{93}$ and reaction temperature changed the yield of the nanocubes. Furthermore, Shengli Qi et al. stated that the basic punch action is annealing. By altering the annealing time at high temperature, the size of the nanocubes could be changed from 90 to $160 \mathrm{~nm} .{ }^{94}$ Jiejun Zhu et al. attempted to produce nanocubes which were obtained at different reaction times of 40 minutes $(70 \mathrm{~nm})$ and $70 \mathrm{~min}(230 \mathrm{~nm})$ at a maximum temperature of $150{ }^{\circ} \mathrm{C}$. XRD and TEM studies

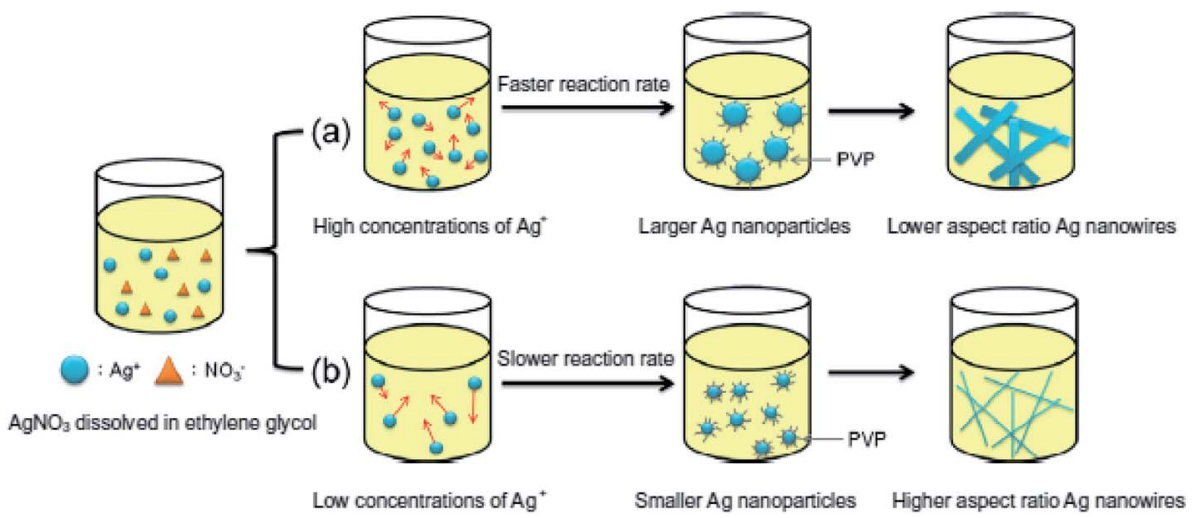

Fig. 9 Schematic of the use of different concentrations of silver nitrate to change the diameters of silver nanowires. ${ }^{77}$ 

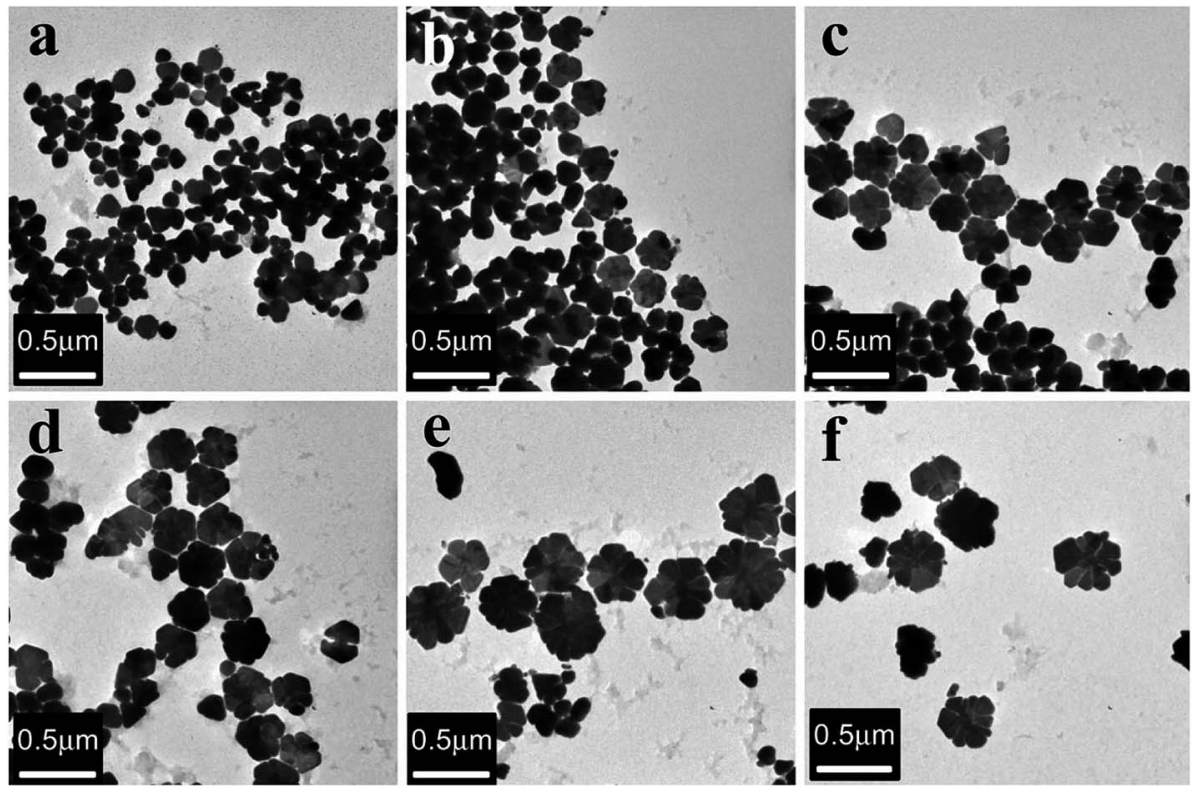

Fig. 10 TEM images of silver nanoproducts synthesized from the extract of Flos Magnoliae officinalis: (a) $2.5 \mathrm{~g} \mathrm{~L}^{-1}$; (b) $5 \mathrm{~g} \mathrm{~L}^{-1}$; (c) $10 \mathrm{~g} \mathrm{~L}^{-1}$; (d) $20 \mathrm{~g}$ $\mathrm{L}^{-1}$; (e) $30 \mathrm{~g} \mathrm{~L}^{-1}$; (f) $40 \mathrm{~g} \mathrm{~L}^{-1}$. 1

showed the presence of sharp edges on the cubes; they were also able to produce/observe nanorods by increasing the reaction time. Also, with increasing time, the edge length of the Ag nanocubes increased. Interestingly, the UV-vis spectra showed SPR peaks at $543 \mathrm{~nm}$ and $665 \mathrm{~nm}$ with increasing reaction time from 40 to $70 \mathrm{~min}$ and SPR peaks at $417 \mathrm{~nm}$ to $461 \mathrm{~nm}$, respectively, at low wavelengths. ${ }^{95}$ Qiyu Wang et al. demonstrated the structure effects on the oxygen reduction reaction (ORR) on similarly sized $\mathrm{Ag}$ dodecahedra and $\mathrm{Ag}$ nanocubes as the working anode; they used a lamp to create the nanocubes. ${ }^{96}$ Qiyu Wang et al. synthesized Ag dodecahedra and Ag nanocubes via an electrochemical method; they also stated that the Ag nanodecahedra had more active sites for catalytic activity than the Ag nanocubes. ${ }^{97} \mathrm{Yi}$ Wang et al. followed a robust method for the facile synthesis of small $\mathrm{Ag}$ nanocubes in the range of 18 to $32 \mathrm{~nm} ;{ }^{98}$ they successfully used diethylene glycol rather than ethylene glycol to produce $\mathrm{Ag}$ nanocubes based on their previous protocol. Ag nanocubes can be synthesized in different nanosize ranges from 10 to $32 \mathrm{~nm}$ depending on the time scale ranging from 30 minutes to 180 minutes, using ethylene glycol..$^{98}$ Andrew R. Siekkinen et al. described the formation of nanocubes using a series of concentrations of $\mathrm{NaS}$ at different temperatures ranging from $145^{\circ} \mathrm{C}$ to $160^{\circ} \mathrm{C}$; during the UV-vis analysis, the SPR peak blue-shifted as the cube length decreased and became closer to spherical. ${ }^{99-101}$

\subsection{Silver nanowires}

Jian Yang Lin et al. clearly proved that the growth of Ag nanowires (NWs) is affected by the synthesis temperature, the concentration of silver nitrate, and the rate at which silver nitrate is added. It has been shown that with changing concentration of $\mathrm{AgNO}_{3}$, the diameter of the $\mathrm{Ag}$ nanowires also decreases and the aspect ratio increases. These nanowires are used for conductive films. Fig. 13 shows the NWs fabricated with different concentrations of $\mathrm{AgNO}_{3}{ }^{102}$ Fig. 14 and 15 show the different morphologies of $\mathrm{Ag}$ NWs at various annealing temperatures. ${ }^{102}$

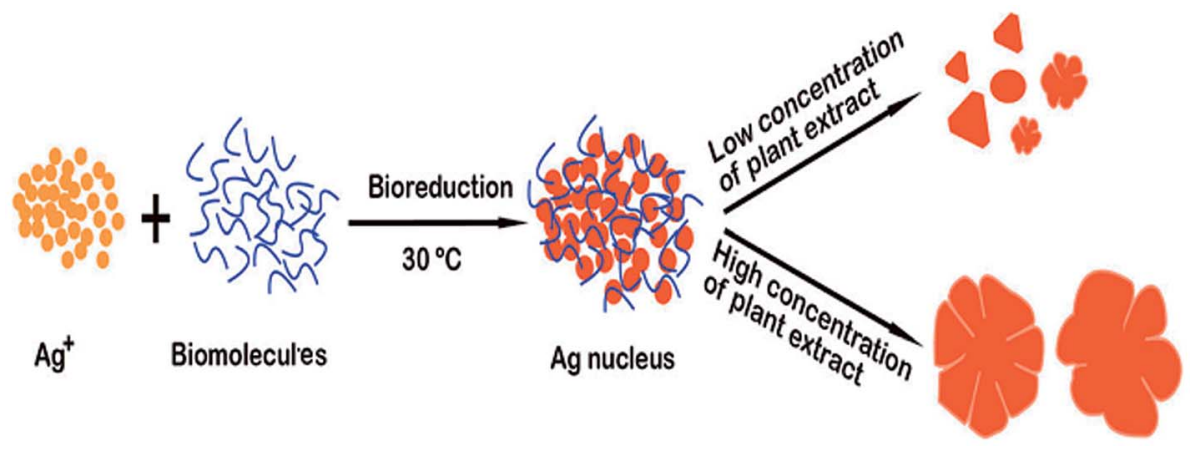

Fig. 11 Schematic of the morphology of Ag structures obtained using Flos Magnoliae officinalis. ${ }^{81}$ 

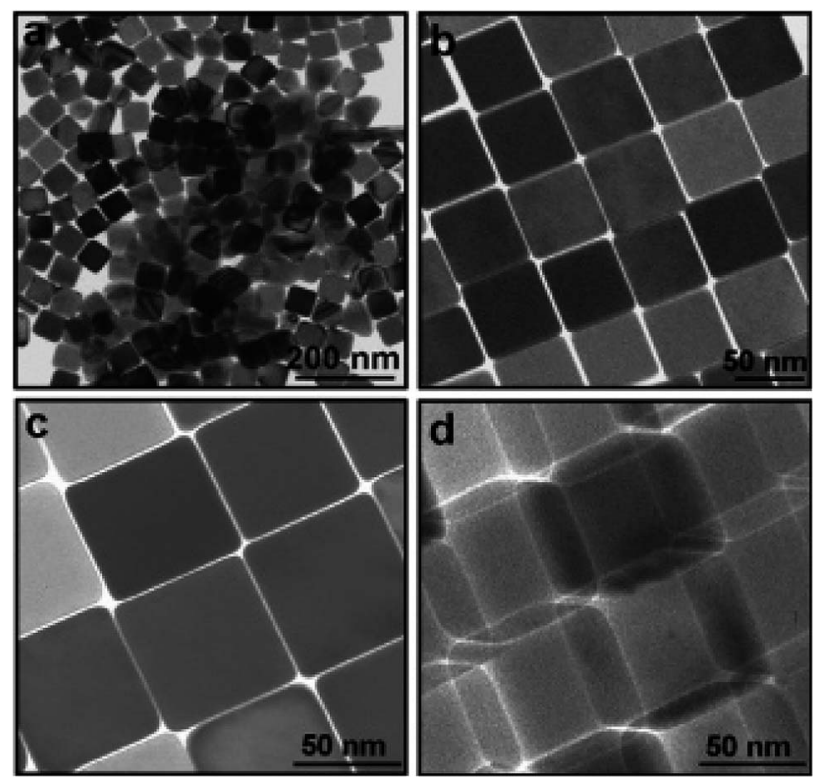

Fig. 12 TEM images of Ag nanocubes: (a) with low magnifications; (bd) with higher magnifications. Images $c$ and $d$ were recorded from almost the same cubes; however, image $d$ was recorded after rotating the cubes by an angle of $30^{\circ} .{ }^{92}$

\subsection{Silver nanotriangles}

Chun fang $\mathrm{Wu}$ et al. demonstrated a simple, reproducible controllable route to synthesize nanotriangles using olive seeds and capping agents; the size could be tuned between 50 and $260 \mathrm{~nm}$ by adjusting the number of seeds or the mole ratio of polyvinyl pyrrolidone [PVP] and $\mathrm{AgNO}_{3} \cdot{ }^{103}$ By changing the dropping speed and using a suitable concentration of trisodium citrate, Ag nanotriangles with sharper corners and narrow size distributions were synthesized. Fig. 16 shows the presence of nanotriangles. Yi He et al. synthesized five silver equilateral triangle plates with thicknesses of $10 \mathrm{~nm}$ and side lengths of 50, 100, 150, 200 and $250 \mathrm{~nm}$, respectively. Ag nanotriangles were synthesized using the discrete dipole approximation (DDA) method. ${ }^{104}$ Similarly, Andrew et al. experimented with synthesizing silver nanoparticles with variable sizes and investigated their optical properties. ${ }^{\mathbf{1 0 5}}$

\section{Applications}

Metal NPs, especially Ag NPs, are interesting because of their superior characteristics, such as magnetic, electrical, and morphology controlled optical activities. These can be exploited in electronic instruments, anti-microbial preparations, cosmetics consumables, biosensor components, cryogenic superconducting parts and composite threads. ${ }^{106}$ Additionally, these nanostructures have numerous uses in various areas, such as curative imaging, nano-hybrids, filters, medicinal transportation and hyperthermia of cancerous cells. ${ }^{\mathbf{1 0 7 , 1 0 8}}$ Nanostructures of metallic Ag have aroused the interest of researchers because of their substantial associated activities in various fields, such as integrated circuits, ${ }^{109}$ bio-tagging, sensors and filters, ${ }^{\mathbf{1 1 0}}$ anti-microbe and deodorant threads, ${ }^{\mathbf{1 1 1}}$ cell electrodes, ${ }^{112} \mathrm{Ag}$ nanowires, economical paper batteries ${ }^{\mathbf{1 1 3}}$ and anti-microbes. ${ }^{114}$ Metallic Ag NPs have been utilized extensively as anti-microbial components in consumable preservation, cloth plating, health concerns and numerous environmental applications.

\subsection{Applications in catalysis}

Nanocatalysis is an emerging area which employs nanostructures as catalysts. It is recognized that elements such as silver, platinum and gold in ionic form can catalyze oxygen formation by degradation of hydrogen peroxide. ${ }^{\mathbf{1 1 4 , 1 1 5}}$ Guo et al. also reported that silver is an important catalyst for the reduction of formaldehyde to methanol and of ethylene oxide to ethylene. Silver nanostructures inactivated on silica spheres were studied for their capability to catalyze the oxidation of dyes by $\mathrm{NaBH}_{4}$ (sodium borohydride). In the absence of silver nanoparticles, there was no motion and no reaction of the dyes. ${ }^{116}$
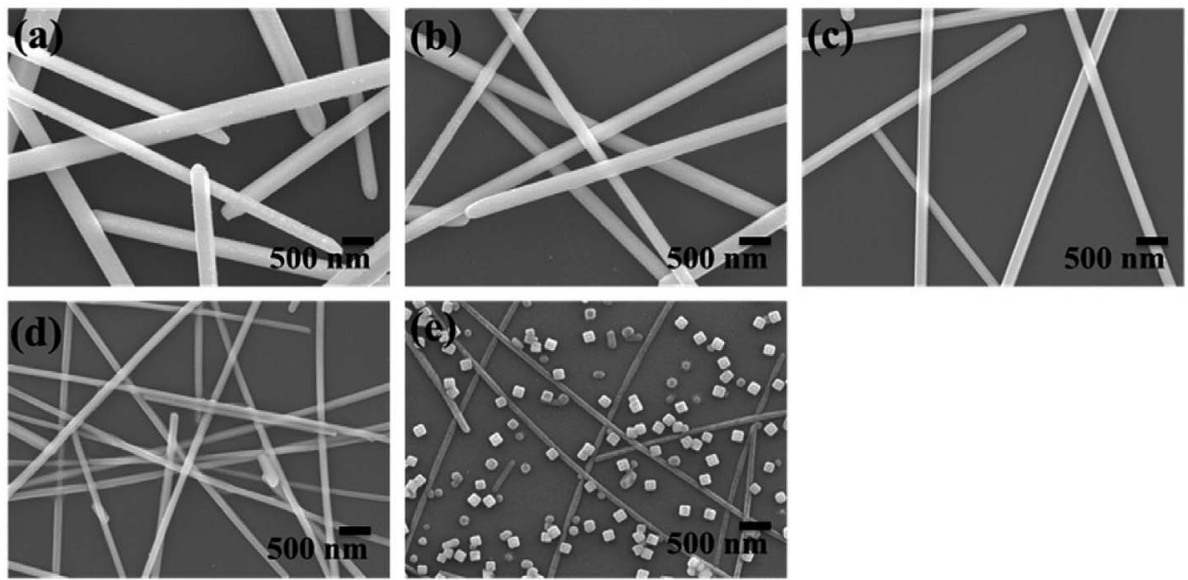

Fig. 13 The synthesis of silver nanowires using different concentrations of silver nitrate; (a)-(e) PVP/silver nitrate molar ratios of 2, 4, 8, 16, and 32, respectively. ${ }^{102}$ 


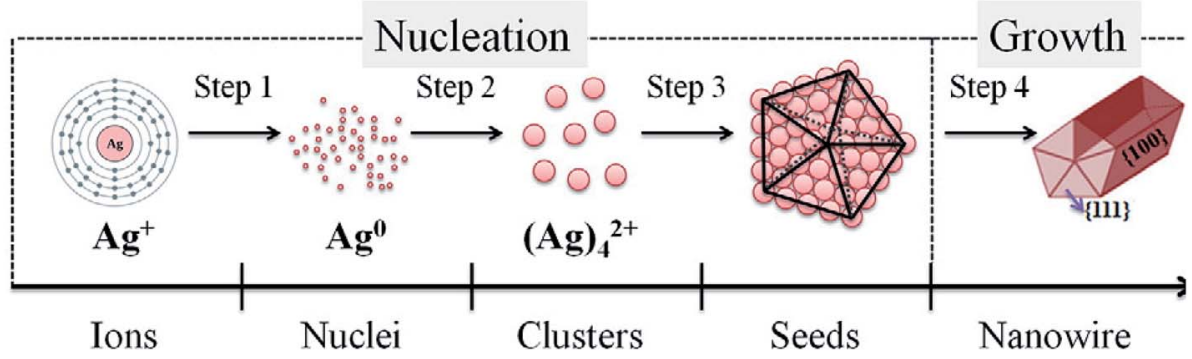

Fig. 14 A simple graph of the mechanism for generating silver nanowires. ${ }^{102}$

\subsection{Electrochemical applications}

Additionally, the electrochemical characteristics of silver NPs in nanorange sensors offer rapid feedback times and lower detection ranges. For example, electrodeposited silver nanostructures on $\mathrm{Al}_{2} \mathrm{O}_{3}$ plates with gold microstructured electrodes manifested very high sensitivity to $\mathrm{H}_{2} \mathrm{O}_{2} \cdot{ }^{117}$ Singaravelan et al. synthesized Ag-NPs via an electrochemical route without using special reagents. The Ag-NPs were characterized by TEM, UV-vis spectroscopy, and FTIR. The optical band gap energy of Ag-NPs $(3.39 \mathrm{eV})$ is a potential candidate for optical and optoelectronic devices. Furthermore, antibacterial activity studies showed acceptable ZoI of Ag-NPs against Gram +ve and Gram -ve bacteria. This property suggests that Ag-NPs can also be used as a bactericidal agent in biomedical applications. ${ }^{118}$

\subsection{Magnetic beads}

Susanne Pahlow et al. prepared silver nanoflowers on magnetic beads, as shown in Fig. 17. ${ }^{119}$ This method is promising because it can be used to easily and inexpensively produce silver nanoflowers-coated magnetic beads which can also be used for surface enhanced Raman scattering (SERS) diagnostics. Hongyan Liang et al. demonstrated the use of $\mathrm{Ag}$ nanoflowers as susceptible substrates of SERS (surface enhanced Raman scattering). Researchers have also stated that Ag nanoflowers can serve as highly sensitive and reproducible SERS substrates. ${ }^{\mathbf{1 2 0}} \mathrm{Ag}$ nanoflowers have many advantages, such as highly sensitive SERS substrates, because these particles are stable and can be reused several times. ${ }^{\mathbf{1 2 0}}$ These particles can be readily synthesized on a large scale, and no byproducts are observed; as a result, the environment will not be polluted. Hence, these nanoflowers are a promising candidate for SERS applications.

\subsection{Optical applications}

The striking optical characteristics of NPs are responsible for their applications in chemosensors and optical biosensors. One of the objectives of investigation is the analysis of bio-binding communication between antigens and antibiotics utilizing triangular silver NPs. ${ }^{\mathbf{1 2 1}}$ Sensitivity is enhanced in the presence of silver nanoparticles to detect zeptomoles. Utilizing the SPR effect, the Ag-NPs attain immense sensitivity, and quantitative analysis can be coordinated in real time. With the help of detectors containing silver nanoparticles, one can examine an organic substance inside a cell as well as observing the dynamical reactions that occur. ${ }^{122}$

\subsection{Plasmonic applications}

Based on the localized surface plasmon resonance (LSPR) of metallic nanoparticles, plasmonic nanosensors have proved to be a powerful tool for biosensing applications. ${ }^{123}$ Lehui Lu et al. synthesized $\mathrm{Ag}$ nanoplates with different sizes by reducing $\left[\mathrm{Ag}\left(\mathrm{NH}_{3}\right)_{2}\right]^{+}$with ascorbic acid. As a result, the flowerlike nanoplates have exhibited good surface-enhanced Raman scattering (SERS) compared to spherical silver nanoparticles. It has also been stated that flowerlike silver nanoplates show potential applications in biological sensing and labeling systems. ${ }^{\mathbf{1 2 4}}$

Mehmet et al. presented a novel method of combining soft lithography and nanosphere lithography to fabricate flexible
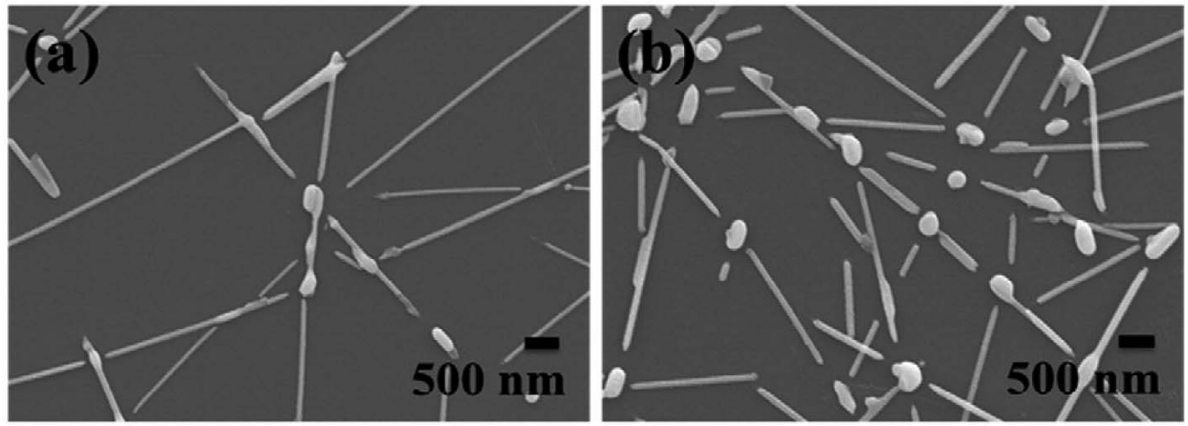

Fig. 15 The surface morphologies of silver nanowires with different annealing temperatures: (a) $300{ }^{\circ} \mathrm{C}$ and (b) $400{ }^{\circ} \mathrm{C} .{ }^{102}$ 

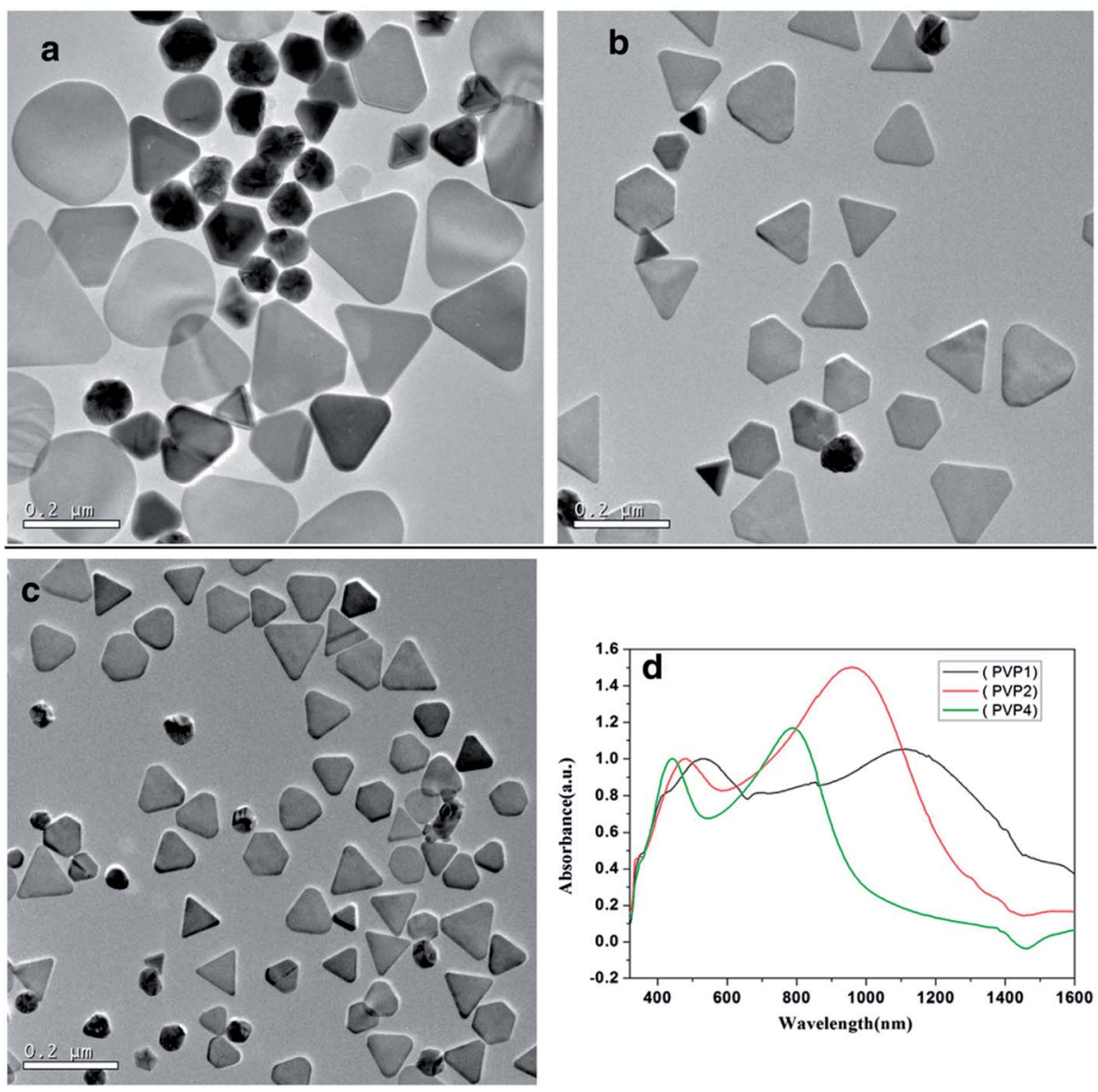

Fig. 16 (a-c) TEM images of as-prepared silver nanotriangles with different molar ratios of PVP and AgNO 3 ; (d) vis-NIR absorption spectra of the corresponding samples. ${ }^{103}$

and tunable plasmonic nanostructures. It has also been observed that the surface plasmon absorption depends on the dimensions (diameter and depth) of the nanostructures. Also, the SERS measurement factor is dependent on the plasmonic absorption wavelength and laser wavelength. ${ }^{125}$

\subsection{Antimicrobial activity}

Fig. 18 shows the antibacterial activity of Ag nanoflowers which are capable of performing diverse biological/clinical applications as stated by Bikash Kumar Jena et al. ${ }^{126}$ The investigators also reported that Ag NPs processed utilizing extracts of leaves from Vitex negundo at a convergence of $2 \mathrm{ppm}$ displayed distinct anti-microbial characteristics against clinically quarantined pathogenic bacteria. In this interesting research, Ag-NPs synthesised from extracts of Vitex negundo leaves had excellent antibacterial characteristics. ${ }^{127,128}$ The processed silver NPs showed strong bacteriostatic motion on Escherichia coli and Staphylococcus aureus; furthermore, they had stronger reactions with Gram negative bacteria than with Gram positive bacteria. ${ }^{129,130}$ The antimicrobial influence of the silver metal NPs showed more influential bacteriostatic effects on the microorganism S. aureus. ${ }^{131,132}$

\subsection{Antifungal activity}

Silver NPs at $50 \mu \mathrm{L}$ displayed advanced antifungal activity against Aspergillus nigeris, Candida albicans and Candida kefyr, while intermediary activity was visualized against $A$. fumigates, C. tropicalis, A. flavus and C. krusei. ${ }^{133,134}$ The assessment of their

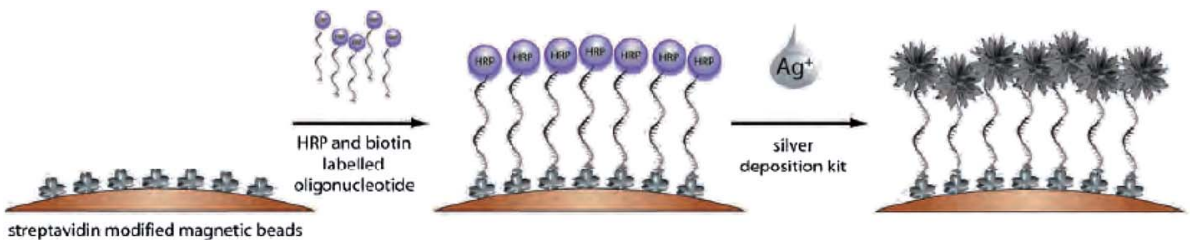

Fig. 17 Scheme of the preparation of silver nanoflowers on magnetic beads. ${ }^{119}$ 


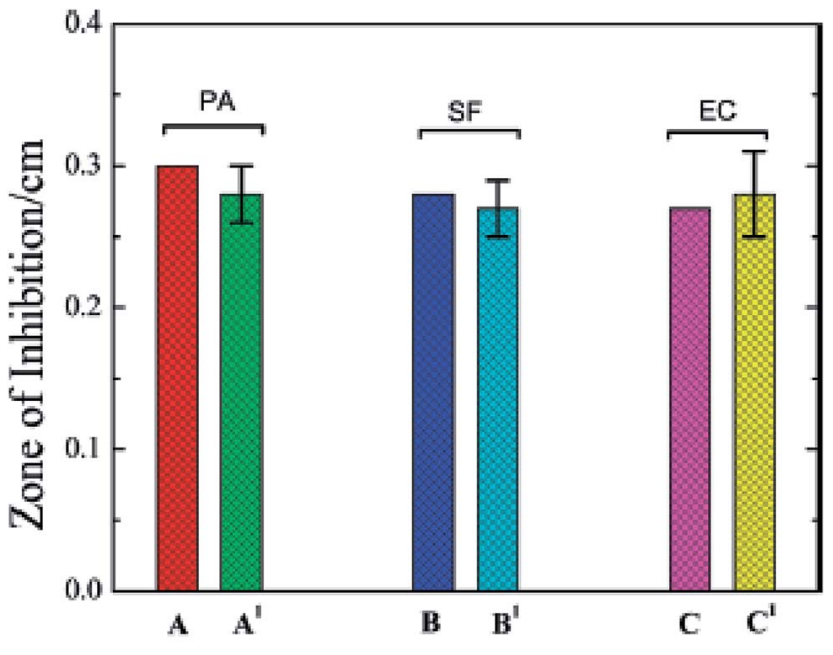

Antibiotic/SNFs

Fig. 18 Plots showing the antibacterial activity of Ag-NFs (SNFs) ( $A^{\prime}-$ $\left.C^{\prime}\right)$ with respect to the standard antibiotics gentamicin (A and $C$ ) and penicillin (B). ${ }^{126}$

antimicrobial activities, such as antifungal and antibacterial, was compared with Ag-NPs. Researchers observed that the lowest prevention concentration of $S$. saprophyticus was $10.19 \pm$ $0.08 \mathrm{mg} \mathrm{mL}^{-1}$, which is lower than that of the other investigated microbes. Uropathogenic Staphylococcus is a type of $S$. saprophyticus which is frequently collected from immature female outpatients with primary urinary zone infections. Silver NPs show dominant antifungal characteristics against $A$. nigeris, $C$. albicans, and C. kefyr. These investigators suggested that silver nanoparticles synthesized by a green method show high antifungal activity. ${ }^{\mathbf{1 3 3 , 1 3 4}}$

\subsection{Antibacterial applications}

Dolgaev et al. claim that Ag-NPs possess indispensable activities in ecological areas, such as DNA sequencing and antimicrobial activity. Silver has been recognized to inhibit the spread of microbes by powerful toxicity (antibacterial activity). ${ }^{135}$ Technologists have acknowledged that Ag-NPs chemically combined with $\mathrm{O}_{2}$ (oxygen) are dangerous to microbes, especially bacteria. ${ }^{136}$ Ag-NPs have numerous applications, such as beauty products, socks, consumable containers, cleansers, sprays and an immense number of different commodities, to hinder the advancement of microbes.

\subsection{Medical applications}

Particular implementations of ionic silver and silver nanoparticles can be deployed in therapeutic applications for burn therapy, teeth parts, sunscreen cosmetics, etc. ${ }^{137,138}$

\section{Conclusions}

The synthesis of $\mathrm{Ag}$ nanostructures with different shapes represents a rapidly growing research area in the field of nanomaterials because of the strong dependence of their properties on their shapes. In this review, the formation and the use of stabilizing agents, where solvents play a major role in the formation of different silver nanostructures, has been presented; also, different shapes of nanoparticles and their applications were studied. Possible methods for the synthesis of various silver nanostructures have been elaborated. An attempt was made to select procedures for synthesizing various shapes of nanoparticles for applications in various fields. It has been observed that the growth of nanoparticles usually follows a trend of three steps, particularly in solution-based methods: these include nucleation, seeding, and growth. It has been observed that the environment of production, parameters during synthesis, thermodynamics, and kinetics at each stage of synthesis have great impacts on the physical and chemical behavior, properties, and control of nanostructures. Among the methods of synthesis of nanosilver, the polyol method is suitable to produce different-shaped nanostructures by changing the reaction conditions. As presented in this review, different structures of nanosilver synthesized by various assembly techniques have varied applications in many fields of science and technology, such as biomedical, electronics, and computers.

\section{Conflicts of interest}

The authors declare no conflict of interest.

\section{References}

1 V. L. Colvin, M. C. Schlamp and A. P. Alivisatos, Nature, 1994, 370, 354.

2 C. Murray, D. J. Norris and M. G. Bawendi, J. Am. Chem. Soc., 1993, 115(19), 8706-8715.

3 G. Schmid, Chem. Rev., 1992, 92, 1709-1727.

4 A. J. Hoffman, G. Mills, H. Yee and M. R. Hoffmann, J. Phys. Chem., 1992, 96, 5546-5552.

5 J. F. Hamilton and R. C. Baetzold, Science, 1979, 205, 12131220.

6 H. S. Mansur, F. Grieser, M. S. Marychurch, S. Biggs, R. S. Urquhart and D. N. Furlong, J. Chem. Soc., Faraday Trans., 1995, 91, 665-672.

7 X. F. Zhang, Z. G. Liu, W. Shen and S. Gurunathan, Int. J. Mol. Sci., 2016, 17, 1534.

8 A. Ali, M. Z. Hira Zafar, I. ul Haq, A. R. Phull, J. S. Ali and A. Hussain, Nanotechnol., Sci. Appl., 2016, 9, 49.

9 M. Shah, D. Fawcett, S. Sharma, S. K. Tripathy and G. E. J. Poinern, Materials, 2015, 8, 7278-7308.

10 M. Imran Din and A. Rani, Int. J. Anal. Chem., 2016, 2016, 114.

11 K. Selvam, C. Sudhakar, M. Govarthanan, P. Thiyagarajan, A. Sengottaiyan, B. Senthilkumar and T. Selvankumar, J. Radiat. Res. Appl. Sci., 2017, 10, 6-12.

12 S. Prabhu and E. K. Poulose, Int. Nano Lett., 2012, 2, 32.

13 P. Singh, Y. J. Kim, H. Singh, C. Wang, K. H. Hwang, M. E. A. Farh and D. C. Yang, Int. J. Nanomed., 2015, 10, 2567.

14 X. Luo, A. Morrin, A. J. Killard and M. R. Smyth, Electroanalysis, 2006, 18, 319-326. 
15 G. Doria, J. Conde, B. Veigas, L. Giestas, C. Almeida, M. Assunção and P. V. Baptista, Sensors, 2012, 12, 16571687.

16 S. Zhang, Y. Tang and B. Vlahovic, Nanoscale Res. Lett., 2016, 11, 80 .

17 P. Dubey, B. Bhushan, A. Sachdev, I. Matai, S. Uday Kumar and P. Gopinath, J. Appl. Polym. Sci., 2015, 132.

18 J. M. Patrascu, I. A. Nedelcu, M. Sonmez, D. Ficai, A. Ficai, B. S. Vasile and L. C. Rusu, J. Nanomater., 2015, 2015, 3.

19 T. M. D. Dang, T. T. T. Le, E. Fribourg-Blanc and M. C. Dang, Adv. Nat. Sci.: Nanosci. Nanotechnol., 2012, 3, 035004.

20 T. Panigrahi, Doctoral dissertation, in Proceedings of the Jangjeon Mathematical Society, ed. T. Panigrahi and G. Murugusundaramoorthy, 2013, vol. 16, ch. 1, pp. 91-100.

21 S. Gajbhiye and S. Sakharwade, J. Cosmet., Dermatol. Sci. Appl., 2016, 6, 48.

22 A. Lohani, A. Verma, H. Joshi, N. Yadav and N. Karki, ISRN Dermatol., 2014, 2014, 1-14.

23 M. J. Firdhouse and P. Lalitha, J. Nanotechnol., 2015, 2015, 1-18.

24 E. Abbasi, M. Milani, S. Fekri Aval, M. Kouhi, A. Akbarzadeh, H. Tayefi Nasrabadi and M. Samiei, Crit. Rev. Microbiol., 2016, 42, 173-180.

25 S. Iravani, H. Korbekandi, S. V. Mirmohammadi and B. Zolfaghari, Res. Pharm. Sci., 2014, 9, 385.

26 T. Klaus-Joerger, R. Joerger, E. Olsson and C. G. Granqvist, Trends Biotechnol., 2001, 19, 15-20.

27 M. Sastry, A. Ahmad, M. I. Khan and R. Kumar, Curr. Sci., 2003, 85, 162-170.

28 S. Iravani, Green Chem., 2011, 13, 2638-2650.

29 H. Korbekandi, S. Iravani and S. Abbasi, Crit. Rev. Biotechnol., 2009, 29, 279-306.

30 F. E. Kruis, H. Fissan and B. Rellinghaus, J. Mater. Sci. Eng. $B, 2000,69,329-334$.

31 Y. Sun, Y. Yin, B. T. Mayers, T. Herricks and Y. Xia, Chem. Mater., 2002, 14, 4736-4745.

32 P. C. Lee and D. Meisel, J. Phys. Chem., 1982, 86, 3391-3395.

33 R. W. Scott, H. Ye, R. R. Henriquez and R. M. Crooks, Chem. Mater., 2003, 15, 3873-3878.

34 I. Sondi, D. V. Goia and E. Matijević, J. Colloid Interface Sci., 2003, 260, 75-81.

35 J. P. Cason, K. Khambaswadkar and C. B. Roberts, Ind. Eng. Chem. Res., 2000, 39, 4749-4755.

36 X. Li, J. Zhang, W. Xu, H. Jia, X. Wang, B. Yang and Y. Ozaki, Langmuir, 2003, 19, 4285-4290.

37 N. Shirtcliffe, U. Nickel and S. Schneider, J. Colloid Interface Sci., 1999, 211, 122-129.

38 S. He, J. Yao, P. Jiang, D. Shi, H. Zhang, S. Xie and H. Gao, Langmuir, 2001, 17, 1571-1575.

39 Y. Wan, Z. Guo, X. Jiang, K. Fang, X. Lu, Y. Zhang and N. Gu, J. Colloid Interface Sci., 2013, 394, 263-268.

40 A. Pyatenko, M. Yamaguchi and M. Suzuki, J. Phys. Chem. C, 2007, 111, 7910-7917.

41 R. Das and S. Sarkar, Opt. Mater., 2015, 48, 203-208.

42 S. Biswas, A. K. Kole, R. Sarkar and P. Kumbhakar, Mater. Res. Express, 2014, 1, 045043.
43 R. Das, S. S. Nath and R. Bhattacharjee, Phys. E, 2010, 43, 224-227.

44 K. D. Rogers and P. Daniels, Biomaterials, 2002, 23, 25772585.

45 R. Das, S. S. Nath and R. Bhattacharjee, J. Lumin., 2011, 131, 2703-2706.

46 S. Link and M. A. El-Sayed, J. Phys. Chem. B, 1999, 103, 84108426.

47 S. Link and M. A. El-Sayed, Int. Rev. Phys. Chem., 2000, 19, 409-453.

48 S. Berciaud, L. Cognet, P. Tamarat and B. Lounis, Nano Lett., 2005, 5, 515-518.

49 S. Hashimoto, D. Werner and T. Uwada, J. Photochem. Photobiol., C, 2012, 13, 28-54.

50 S. H. Im, Y. T. Lee, B. Wiley and Y. Xia, Angew. Chem., 2005, 117, 2192-2195.

51 Y. M. Chang, I. T. Lu, C. Y. Chen, Y. C. Hsieh and P. W. Wu, J. Alloys Compd., 2014, 586, 507-511.

52 Y. Wang, Y. Zheng, C. Z. Huang and Y. Xia, J. Am. Chem. Soc., 2013, 135, 1941-1951.

53 I. Capek, Nanocomposite structures and dispersions, Elsevier, 2006, p. 23.

54 Q. Zhang, W. Li, L. P. Wen, J. Chen and Y. Xia, Chem.-Eur. J., 2010, 16, 10234-10239.

55 Q. Zhang, N. Li, J. Goebl, Z. Lu and Y. Yin, J. Am. Chem. Soc., 2011, 133, 18931-18939.

56 V. Germain, J. Li, D. Ingert, Z. L. Wang and M. P. Pileni, J. Phys. Chem. B, 2003, 107, 8717-8720.

57 B. Rodríguez-González, I. Pastoriza-Santos and L. M. LizMarzán, J. Phys. Chem. B, 2006, 110, 11796-11799.

58 R. Jin, Y. Cao, C. A. Mirkin, K. L. Kelly, G. C. Schatz and J. G. Zheng, Science, 2001, 294, 1901-1903.

59 L. M. Liz-Marzán, Langmuir, 2006, 22, 32-41.

60 I. Pastoriza-Santos and L. M. Liz-Marzán, Nano Lett., 2002, 2, 903-905.

61 Y. Sun, B. Mayers and Y. Xia, Nano Lett., 2003, 3, 675-679.

62 F. Fiévet and R. Brayner, The polyol process. Nanomaterials: A Danger or a Promise?, Springer, London, 2013, pp. 1-25.

63 S. J. Jeon, J. H. Lee and E. L. Thomas, J. Colloid Interface Sci., 2014, 435, 105-111.

64 B. Wiley, T. Herricks, Y. Sun and Y. Xia, Nano Lett., 2004, 4, 1733-1739.

65 L. Au, S. E. Skrabalak, X. Li and Y. Xia, Nat. Protoc., 2007, 2, 2182.

66 S. Omobayo Adio, C. Basheer, K. Zafarullah, A. Alsharaa and Z. Siddiqui, Int. J. Environ. Anal. Chem., 2016, 96, 776-788.

67 Y. Sun, Y. Yin, B. T. Mayers, T. Herricks and Y. Xia, Chem. Mater., 2002, 14, 4736-4745.

68 Q. N. Luu, J. M. Doorn, M. T. Berry, C. Jiang, C. Lin and P. S. May, J. Colloid Interface Sci., 2011, 356, 151-158.

69 Y. Zhou, S. H. Yu, X. P. Cui, C. Y. Wang and Z. Y. Chen, Chem. Mater., 1999, 11, 545-546.

70 L. M. Huang, H. T. Wang, Z. B. Wang, A. Mitra, K. N. Bozhilov and Y. S. Yan, Adv. Mater., 2002, 14, 61.

71 J. H. Song, Y. Wu, B. Messer, H. Kind and P. Yang, J. Am. Chem. Soc., 2001, 123, 10397-10398. 
72 H. Jiang, J. Jiang, J. Cheng, W. Dou, X. Tang, L. Yang and D. Bai, New J. Chem., 2014, 38, 109-114.

73 L. Liu, C. He, J. Li, J. Guo, D. Yang and J. Wei, New J. Chem., 2013, 37, 2179-2185.

74 L. M. Huang, H. T. Wang, Z. B. Wang, A. Mitra, K. N. Bozhilov and Y. S. Yan, Adv. Mater., 2002, 14, 61.

75 S. J. Hurst, E. K. Payne, L. Qin and C. A. Mirkin, Angew. Chem., Int. Ed., 2006, 45, 2672-2692.

$76 \mathrm{Liu}$ and $\mathrm{Yu}$, Nanoscale Res. Lett., 2011, 6, 75.

77 L. Rodriguez-Sanchez, M. C. Blanco and M. A. LopezQuintela, J. Phys. Chem. B, 2000, 104, 9683-9688.

78 N. M. Abbasi, H. Yu, L. Wang, W. A. Amer, M. Akram, H. Khalid and J. Shan, Mater. Chem. Phys., 2015, 166, 1-15.

79 C. Yang, Y. Tang, Z. Su, Z. Zhang and C. Fang, J. Mater. Sci. Technol., 2015, 31, 16-22.

80 S. Hemmati, D. P. Barkey, N. Gupta and R. Banfield, ECS J. Solid State Sci. Technol., 2015, 4(4), P3075-P3079.

81 X. Jing, J. Huang, L. Wu, D. Sun and Q. Li, J. Nanopart. Res., 2014, 16, 2327.

82 B. K. Jena, B. K. Mishra and S. Bohidar, J. Phys. Chem. C, 2009, 113, 14753-14758.

83 D. F. Zhang, L. Y. Niu, L. Jiang, P. G. Yin, L. D. Sun, H. Zhang and C. H. Yan, J. Phys. Chem. C, 2008, 112, 16011-16016.

84 C. J. Orendorff, A. Gole, T. K. Sau and C. J. Murphy, Anal. Chem., 2005, 77, 3261-3266.

85 X. Ma, Q. Guo, Y. Xie and H. Ma, Chem. Phys. Lett., 2016, 652, 148-151.

86 C. J. Orendorff, A. Gole, T. K. Sau and C. J. Murphy, Anal. Chem., 2005, 77, 3261-3266.

87 Y. Wang, Y. Zheng, C. Z. Huang and Y. Xia, J. Am. Chem. Soc., 2013, 135(5), 1941-1951.

88 D. Yu and V. W. W. Yam, J. Am. Chem. Soc., 2004, 126, 13200-1320189.

89 D. Yu and V. W. W. Yam, J. Phys. Chem. B, 2005, 109(12), 5497-5503.

90 B. Jiang, M. Li, F. Bai, H. Yu, T. Mwenya, Y. Li and D. Song, AIP Adv., 2013, 3, 032119.

91 Y. Sun and Y. Xia, Science, 2002, 298, 2176-2179.

92 D. Yu and V. W. W. Yam, J. Phys. Chem. B, 2005, 109(12), 5497-5503.

93 E. V. Panfilova, B. N. Khlebtsov, A. M. Burov and N. G. Khlebtsov, Colloid J., 2012, 74, 99-109.

94 S. Qi, X. Shen, Z. Lin, G. Tian, D. Wu and R. Jin, Nanoscale, 2013, 5, 12132-12135.

95 J. J. Zhu, C. X. Kan, J. G. Wan, M. Han and G. H. Wang, J. Nanomater., 2011, 2011, 40.

96 Q. Wang and Q. Lu, Nat. Commun., 2017, 8, 709.

97 Q. Wang, C. U. I. Xiaoqiang, W. Guan, L. Zhang, X. Fan, Z. Shi and W. Zheng, J. Power Sources, 2014, 269, 152-157.

98 Y. Wang and N. Herron, J. Phys. Chem., 1991, 95, 525-532.

99 R. Jin, C. Zeng, M. Zhou and Y. Chen, Chem. Rev., 2016, 116, 10346-10413.

100 A. R. Siekkinen, J. M. McLellan, J. Chen and Y. Xia, Chem. Phys. Lett., 2006, 432, 491-496.

101 B. Wiley, T. Herricks, Y. Sun and Y. Xia, Nano Lett., 2004, 4, 1733-1739.
102 J. Y. Lin, Y. L. Hsueh, J. J. Huang and J. R. Wu, Thin Solid Films, 2015, 584, 243-247.

103 C. Wu, X. Zhou and J. Wei, Nanoscale Res. Lett., 2015, 10, 354.

104 Y. He and G. Shi, J. Phys. Chem. B, 2005, 109, 17503-17511.

105 A. J. Frank, N. Cathcart, K. E. Maly and V. Kitaev, J. Chem. Educ., 2010, 87, 1098-1101.

106 S. Hemmati, D. P. Barkey, N. Gupta and R. Banfield, ECS J. Solid State Sci. Technol., 2015, 4, P3075-P3079.

107 M. A. Albrecht, C. W. Evans and C. L. Raston, Green Chem., 2006, 8, 417-432.

108 D. Pissuwan, S. M.Valenzuela and M. B. Cortie, Trends Biotechnol., 2006, 24, 62-67.

109 M. Tan, G. Wang, Z. Ye and J. Yuan, J. Lumin., 2006, 117, 2028.

110 S. Kotthaus, B. H. Gunther, R. Hang and H. Schafer, IEEE Trans. Compon., Packag., Manuf. Technol., Part A, 1997, 20, 15-20.

111 G. Cao, Nanostructures \& nanomaterials: synthesis, properties \& applications, Imperial College Press, 2004.

112 W. Z. Zhang and G. Wang, New Chem. Mater., 2003, 31, 4244.

113 L. Hu, J. W. Choi, Y. Yang, S. Jeong, F. La Mantia, L. F. Cui and Y. Cui, Proc. Natl. Acad. Sci., 2009, 106, 21490-21494.

114 K. H. Cho, J. E. Park, T. Osaka and S. G. Park, Electrochim. Acta, 2005, 51, 956-960.

115 G. Merga, R. Wilson, G. Lynn, B. H. Milosavljevic and D. Meisel, J. Phys. Chem. C, 2007, 111, 12220-12226.

116 J. Z. Guo, H. Cui, W. Zhou and W. Wang, J. Photochem. Photobiol., A, 2008, 193, 89-96.

117 Z. J. Jiang, C. Y. Liu and L. W. Sun, J. Phys. Chem. B, 2005, 109, 1730-1735.

118 R. Singaravelan and S. B. Alwar, Appl. Nanosci., 2015, 5, 983-991.

119 D. Cialla, K. Weber, J. Popp, S. Pahlow and A. März, Tagungsband, 2013, 345-350.

120 H. Liang, Z. Li, W. Wang, Y. Wu and H. Xu, Adv. Mater., 2009, 21(45), 4614-4618.

121 X. Xu, Y. Ma, Y. Du, T. Jiang, J. Zhou and Z. Zhao, Mater. Res. Express, 2018, 5, 015013.

122 S. Zhu, C. Du and Y. Fu, Opt. Mater., 2009, 31, 769-774.

123 L. Guo, J. A. Jackman, H. H. Yang, P. Chen, N. J. Cho and D. H. Kim, Nano Today, 2015, 10, 213-239.

124 L. Lu, A. Kobayashi, K. Tawa and Y. Ozaki, Chem. Mater., 2006, 18, 4894-4901.

125 M. Kahraman, P. Daggumati, O. Kurtulus, E. Seker and S. Wachsmann-Hogiu, Sci. Rep., 2013, 3, 3396.

126 B. K. Jena, B. K. Mishra and S. Bohidar, J. Phys. Chem. C, 2009, 113, 14753-14758.

127 M. C. Estevez, M. A. Otte, B. Sepulveda and L. M. Lechuga, Anal. Chim. Acta, 2014, 806, 55-73.

128 M. Ahmad, N. Ghafoor and M. N. Aamir, Indian J. Pharm. Sci., 2012, 74, 465.

129 Y. He, Z. Du, H. Lv, Q. Jia, Z. Tang, X. Zheng and F. Zhao, Int. J. Nanomed., 2013, 8, 1809.

130 W. K. Jung, H. C. Koo, K. W. Kim, S. Shin, S. H. Kim and Y. H. Park, Appl. Environ. Microbiol., 2008, 74, 2171-2178. 
131 J. Suriya, S. B. Raja, V. Sekar and R. Rajasekaran, Afr. J. Biotechnol., 2012, 11, 12192-12198.

132 S. B. Almasaudi, A. A. Al-Nahari, M. El Sayed, E. Barbour, S. M. Al Muhayawi, S. Al-Jaouni and S. Harakeh, Saudi J. Biol. Sci., 2017, 24, 1255-1261.

133 Y. Rout, S. Behera, A. K. Ojha and P. L. Nayak, J. Microbiol. Antimicrob., 2012, 4, 103-109.

134 A. Lalitha, R. Subbaiya and P. Ponmurugan, Int. J. Curr. Microbiol. Appl. Sci., 2013, 2, 228-235.
135 S. I. Dolgaev, A. V. Simakin, V. V. Voronov, G. A. Shafeev and F. Bozon-Verduraz, Appl. Surf. Sci., 2002, 186, 546-551.

136 S. Agnihotri, S. Mukherji and S. Mukherji, RSC Adv., 2014, 4, 3974-3983.

137 A. Schmidt-Ott, J. Aerosol Sci., 1988, 19, 553559-557563.

138 N. Durán, P. D. Marcato, G. I. De Souza, O. L. Alves and E. Esposito, J. Biomed. Nanotechnol., 2007, 3, 203-208. 